\title{
HUBUNGAN PENGETAHUAN TENTANG APD PEMBUATAN TAHU TERHADAP PENGGUNAAN ALAT PELINDUNG DIRI OLEH PEKERJA PABRIK TAHU WARDI DI JL.CIPTA KARYA DAN PAYUNG SEKAKI KOTA PEKANBARU 2020
}

\author{
Neneng Sanjaya ${ }^{1)}$ Putri Wulandini ${ }^{2)}$,Roni Saputra ${ }^{3)}$ \\ ${ }^{123}$ Prodi D III Keperawatan Universitas Abdurrab \\ Email: Nenengsanjaya@studentunivrab.ac.id
}

\begin{abstract}
Knowledge of personal protective equipment (PPE) is a worker's understanding of various matters relating to personal protective equipment used at work, obedient workers have the knowledge and awareness to protect themselves against safety hazards and will behave safely in carrying out their work. This study aims to determine whether there is a Knowledge Relationship about Tofu Makers to the Use of Personal Protective Equipment by Tofu Factory Workers at Jl.Cipta Karya and Kec.Payung Sekaki Pekanbaru City.The method of collecting data in this study through observation and questionnaire methods and library research to in this study were 38 Tofu factory workers on Jl.Cipta Karya and Kec.Payung Sekaki Pekanbaru City. The Sampling Technique used was the Total Sampling Technique, Total Sampling was a sampling technique where the number of samples was equal to the total population. The results of the analysis of this study using the statistics of 38 respondents who know well, 1 person (100\%) and know enough 15 people (83.3\%), and know less than 14 people (73.3\%) based on statistical test results obtained $p$ value $=0.673$, it can be concluded that there is a relationship that knows knowledge about PPE on Jl.Cipta Karya and Tofu Factory located in Payung Sekaki District.The results of the analysis do not have a relationship between knowledge and the use of PPE proven in the data analysis shows that there were 30 people or $78.9 \%$ who did not use PPE completely and it could be stated that their knowledge was lacking.
\end{abstract}

Keywords: Knowledge, Use, PPE

\begin{abstract}
ABSTRAK
Pengetahuan masyarakat mengenai alat pelindung diri berupa pemahaman seseorang tentang hal hal yang berkaitan dengan segala sesuatu mengenai alat pelindung diri ketika bekerja, seseorang bekerja memiliki rasa patuh, pengetahuan serta kesadaran memberikan perlindungan terhadap keselamatan saat bekerja akan bertindak aman saat bekerja. Tujuan dari penetilian ini yakni untuk mengetahui apakah ada Hubungan Pengetahuan Tentang APD Pembuat Tahu Terhadap Penggunaan Alat Pelindung Diri Oleh Pekerja Pabrik Tahu di Jl.Cipta Karya dan Kec.Payung Sekaki Kota Pekanbaru.Metode Pengumpulan data pada penelitian ini melalui observasi dan metode kuesioner dan penelitian kepustakaan sampai dalam penelitian ini adalah 38 pekerja pabrik tahu Tahu di Jl.Cipta Karya dan Kec.Payung Sekaki Kota Pekanbaru. Penelitian dengan Teknik Total Sampling, Total sampling adalah teknik pengambilan sampel dimana jumlah sampel sama dengan jumlah populasi. Hasil analisis penelitian ini dengan menggunakan statistik 38 responden yang mengetahui baik, 1 orang $(100 \%)$ dan mengetahui cukup 15 orang $(83,3 \%)$,dan mengetahui kurang 14 orang $(73,3 \%)$ dari hasil uji SPSS/ statistik nilai $\mathrm{p}$ value yang diperoleh yakni $=0,673$, ini bermakna terdapat hubungan yang mengetahui pengetahuan tentang APD di Jl.Cipta Karya dan Pabrik Tahu yang berada di Kec.payung Sekaki.Hasil dari analisis tidak terdapat hubungan pengetahuan dan penggunaan APD terbukti dalam analisa data menunjukkan bahwa terdapat 30 orang atau $78,9 \%$ yang tidak menggunakan APD dengan lengkap dan dapat dinyatakan pengetahuan mereka kurang.
\end{abstract}

Kata Kunci :Pengetahuan,Penggunaan,APD 
Jurnal Keperawatan Abdurrab

Vol 4. No.1, Juli 2020
P-ISSN : 2541-2620

E-ISSN : 2579-8723

\section{PENDAHULUAN}

Perkembangan Industri di Indonesia sampai sekarang ini masih terus ditingkatkan dimana pembangunan dibidang industri mempunyai peranan penting dalam mencapai tujuan pembangunan Nasional Kesehatan dan harus diselenggarakan sebagai bagian integral, menurut Undang-Undang Kesehatan No.23

Tahun 1992 pasal 23 Kesehatan dan Keselamatan Kerja yakni melaksanakana pemeliharaan, memberikan maksimal pada kesehatan fisik, kesehatan mental serta kesejahteraan sosial, pelaksanaan manajemen cegah risiko agar terhindar dari kecelakaan kerja, melindungi pekerja cegah resiko agar terhindar dari hal hal yang dapat merugikan kesehatan, (WHO, 2010).

Kecelakaan saat bekerja pada tempat

kerja disebabkan oleh banyak hal yang berkaitan satu sama lain yang mana dapat menimbulkan kematian, cacat fisik serta PAK. Data di Indonesia Provinsi Triwulan IV berikut tipe kecelakaan keja tahun 2014, Jawa Tengah terdapat kecelakaan kerja dan korban 3.107 jiwa dan PAK (Pusdatinaker, 2014).

Di Indonesia Penyebab yang sangat berperan terjadinya kecelakaan kerja adalah karena tindakan yang tidak aman (unsafe action) 31.776 kasus $(32.06 \%$ dari total kasus) dan 57.626 kasus $(58,15 \%$ dari total kasus) (Jamsostek, 2011). Tindakan tidak aman ini yakni tindakan membahayakan pekerja, lingkungan orang lain pekerja sehingga kecelakaan kerja terjadi karna berbagai hal . berikut contoh tidak menggunakan alat pelindung diri (APD), tidak mengikuti SOP saat bekerja, tidak mengikuti aturan keselamatan kerja dan kurang berhatihati (Pratiwi, 2012).

Pengetahuan itu sendiri merupakan hasil dari tahu setelah orang melakukan analisis pengindraan pada objek tertentu. Ini terjadi melalui pancaindra manusia, dimana pengetahuan manusia didapatkan melalui mata serta telinga. Pengetahuan maupun kognitif sebagai domain sangat penting dalam pembentukan tindakan manusia (Notoatmodjo, 2011).

Faktor dominan prilaku salah satunya Pengetahuan yang membentuk tindakan manusia. Proses terjadinya pembelajaran sendiri disebabkan faktor keadaan subyek ketika belajar seperti intelegensi manusia, daya tangkap manusia, ingatan manuasi, motivasi dan sebagainya. Sehingga pengetahuan manusia berperan penting terhadap tindakan (Notoatmojo 2008).

Alat pelindung diri sendiri digunakan pekerja saat pekerjaan dengan memenuhi kriteria masing-masing ini ber tujuan memberikan perlindungan pekerja selama bekerja guna terpenuhi kenyamanan dan keselamatan bekerja(Suma'mur, 2010).

Standard Oprasional Prosedur (SOP) saat meenggunaan Alat Pelindung Diri (APD) diperiksa terlebih dahulu untuk melihat kondisi APD sesuai dengan kebutuhan dan jenis pekerjaan. Ketersedian sarana, perawatan serta APD pada pekerja pembuat tahu ditentukan pengelola pabrik tahu. Sehingga dapat mencegah para pekerja tahu 
terpapar hal hal yang berbaha dari limbah pengelolahan tahu (Notoatmodjo,2012).

Mengapa penting pemakaian alat pelindung diri karena bertujuan untuk mencegah kecelakaan

kerja saat melakukan tindakan dan sarana atau fasilitas untuk dapat mencegah ,terpapar atau terkontaminasi dengan faktorfaktor biologi yang berasal dari limbah pengelolahan tahu.

Persiapan alat-alat APD merupakan tindakan sangat penting dan perlu mendapat prioritas guna mengurangi kondisi parah jika terjadi kecelakaan. sistem ataupun SOP, status dari ekonomi dan kebijakan politik (Hermansyah, 2016)

Tahu Terhadap Alat Pelindung Diri Oleh Pekerja Pabrik Tahu Wardi di Jl.Cipta Karya dan Kec.Payung Sekaki Kota Pekanbaru

2020. Tujuan peneliti Mengetahui Hubungan Pengetahuan tentang APD Pembutan Tahu Terhadap Penggunaan Alat Pelindung Diri (APD) Oleh Pekerja Pabrik Tahu di Jl.Cipta Karya dan Kec.Payaung Sekaki di Kota Pekanbaru 2020.

\section{METODE PENELITIAN}

Korelasi, sehingga dapat terlihat hubungan yang akurat dan sejumlah dari sejumlah karakteristik masalah yang diteliti.Penelitian ini dilakukan di di Pabrik Tahu Wardi yang berada Jl.Cipta Karya dan Pabrik tahu yang berada di Kec.Payung Sekaki Kota Pekanbaru pada Bulan Oktober 2019- Bulan Februari 2020).Populasi adalah keseluruhan subyekpenelitian. Dalam penelitian ini, jumlah populasi yang ada sebanyak 38
Dari hasil wawancara pemilik pembuatan tahu menyatakan pekerjanya belum lengkap menggunakan APD karena belum cukup biaya untuk membelinya,dan pekerja pembuatan tahu hanya menggunakan sepatu boot dan baju pelindung,dan pemimpin pebuatan tahu juga mengatakan pekerjanya tidak terlalu menggunakan APD karena merasa tidak nyaman saat bekerja dan merasa mengganggu dan memperlambat bekerja saja.

Hal diatas dapat menjawab apakah terdapat Hubungan Pengetahuan Tentang APD Pembuatan

orang pekerja pembuatan tahu yang bekerja di Pabrik Tahu Wardi yang berada Jl.Cipta Karya dan Pabrik tahu yang berada di Kec.Payung Sekaki Kota Pekanbaru. Penelitian ini adalah total sampling teknik penentuan sampel dengan semua anggota populasi digunakan sebagai sample (Nursalam, 2010). Dengan kuesioner serta lembar observasi.

\section{HASIL DAN PEMBAHASAN}

\section{HASIL}

Distribusi frekuensi Hasil penelitian tentang pengetahuan mengenai alat pelindung diri pada responden dapat dike tahui bahwa dari 38 responden memiliki pengetahuan baik yaitu $2,6 \%$ sebanyak 1 orang, yang memiliki pengetahuan cukup yaitu $47,3 \%$ sebanyak 18 orang dan yang memiliki pengetahuan kurang yaitu 50\% sebanyak 19 orang.

Distribusi Frekuensi Hasil Penelitian tentang Penggunaan Alat Pelindung Diri 
Jurnal Keperawatan Abdurrab

Vol 4. No.1, Juli 2020

Oleh Pekerja Pabrik Tahu menunjukkan bahwa para pekerja yang menggunakan APD dengan lengkap sebanyak 8 yaitu 7,9 $\%$ orang mereka merasa nyaman memakai alat pelindung diri saat bekerja dan tidak menggunakan APD dengan lengkap sebanyak 30 yaitu $78,94 \%$ orang dikarnakan mereka merasa tidak nyaman dalam memakai alat pelindung diri saat bekerja. Distribusi Frekuensi mengetahui Hubungan tentang Penggunaan Alat Pelindung Diri Oleh Pekerja Pabrik Tahu dapat kita lihat bahwa dari 38 yang mengetahui baik,1 orang $(100 \%)$ dan mengetahui cukup 15 orang $(83,3 \%)$,dan mengetahui kurang 14 orang $(73,3 \%)$ berdasarkan hasil uji statistik diperoleh nilai $\mathrm{p}$ value $=0,673$, maka dapat disimpulkan bahwa terdapat hubungan yang mengetahui pengetahuan tentang APD di Jl.Cipta Karya dan Pabrik Tahu yang berada di Kec.payung Sekaki.

\section{PEMBAHSAN}

\section{Pengetahuan Tentang APD}

Berdasarkan hasil penelitian tentang pengetahuan mengenai alat pelindung diri pada responden dapat diketahui bahwa dari 38 responden memiliki pengetahuan baik yaitu 2,6\% sebanyak 1 orang, yang memiliki pengetahuan cukup yaitu $47,3 \%$ sebanyak 18 orang dan yang memiliki pengetahuan kurang yaitu 50\% sebanyak 19 orang. di Pabrik Tahu di Jl. Cipta Karya dan Kec Payung Sekaki Kota Pekanbaru hasil yakni pengetahuan pekerja belum baik, yakni pekerja tidak mengetahui pengertian APD, manfaat menggunakan, syarat dari APD, dan apasaja alat pelindung diri yang

\section{P-ISSN : 2541-2620}

E-ISSN : 2579-8723

baik itu pada pembuat tahu. Hal ini disebabkan kurangnya sumber informasi. Pengetahuan merupakan hal yang sangat penting. Dimana apabila pengetahuan baik, makan perilaku APD mengikuti. (Notoatmodjo, 2013).

Menurut asumsi peneliti,pengetahuan pekerja pembuatan tahu sangat erat hubungannya dengan pendidikan,dengan tingginya pendidikan maka pekerja untuk mengetahui lebih jelas dan memahami lebih banyak tentang APD saat bekerja.

\section{Penggunaan APD}

Hasil penelitian tabel di atas menunjukkan bahwa para pekerja yang menggunakan APD dengan lengkap sebanyak 8 yaitu $7,9 \%$ orang 83 a merasa nyaman memakai alat pelindung diri saat bekerja dan tidak menggunakan APD dengan lengkap sebanyak 30 yaitu $78,94 \%$ orang dikarnakan mereka merasa tidak nyaman dalam memakai alat pelindung diri saat bekerja.

Penggunaan Alat Pelindung Diri (APD) Tentunya harus diperiksa terlebuh dahulu apakah kondisinya sesuai dengan Standard Oprasional Prosedur (SOP) dan APD yang digunakan harus disesuaikan dengan kebutuhan dan jenis pekerjaan.ketersedian APD pada tenaga kerja pengelolah tahu Tergantung pada pabrik atau dimana pekerja melakukan kegiatan,Penggunaan alat pelindung diri adalah salah satu sarana atau fasilitas untuk dapat mencegah ,terpapar atau terkontaminasi dengan faktor-faktor biologi yang berasal dari limbah 
Jurnal Keperawatan Abdurrab

Vol 4. No.1, Juli 2020

pengelolahan tahu (Notoatmodjo,2012).

Menurut asusmi penelitian,apabila tidak menggunakan alat penggunaan pelidung tersebut maka akan terjadi hal yang tidak di inginkan seperti kutu air yang sebabkan karena terlalu lama dalam air atau sepatu boot yang digunakan lembab.

\section{Hubungan pengetahuan dalam}

Penggunaan APD

Berdasarkan hasil dari penelitian ini mengunggkapkan bahwa tidak terdapat hubungan pengetahuan dan penggunaan APD karena dari hasil uji statistik hanya terlihat perbedaan tipis antara hubungan pengetahuan dan penggunaan APD.terbukti dalam analisa data menunjukkan bahwa terdapat 30 orang atau $78,9 \%$ yang tidak menggunakan APD dengan lengkap dan dapat dinyatakan pengetahuan mereka kurang.

\section{KESIMPULAN}

Untuk Mengetahui Pengetahuan Pekerja Pembuatan Tahu Terhadap Penggunaan APD di Pabrik Tahu Wardi yang berada di Jl.Cipta Karya dan Pabrik Tahu yang berada di Jl.Fajar payung Sekaki. sebagian besar adalah dari 38 responden memiliki pengetahuan baik dalam menggunakan APD dengan Lengkap yaitu $0 \%$, yang memiliki pengetahuan cukup yaitu $16,7 \%$ sebanyak 3 orang.

\section{DAFTAR PUSTAKA}

Agus, Riyanto. (2013).Kapita Salekta Kuisener Pengetahuan Dan Sikap Dalam Penelitian Kesehatan.
P-ISSN : 2541-2620

E-ISSN : 2579-8723

Jakarta: Salemba Medika.

Alamsyah Dan Muliawati (2013).Keselamatan Kerja. Yogyakarta: Nuha Medika.PT Jamsostek. (Persero).

Jamsostek Alami Kecelakaan Kerja. Retrieved Desember 12, 2019, From Sindonews: $\quad$ Http://Ekbis. Sindonews.Com/Read/836859/34/19 2-911-Peserta-JamsostekalamiKecelakaan- Kerja.

Notoatmodjo. (2010).Metodologi Penelitian Pengetahuan, Sikap, Dan Perilaku Manusia.

Yogyakarta: Nuha Medika.

Notoatmodjo. (2012).Pengetahuan Alat Pelindung Diri Perawat. Jakarta: Erlangga.

Riyanto. (2013).Pengukuran Ilmu Keperawatan . Salemba Empat: Jakarta.

Sugiyono, metode penelitian pendidikan(pendek Sugiyono atan kuantitatif, kualitatif, dan $R \& D)$ Bandung:Alfabeta,2012)

Sihombing, FD. (2014).Faktor - faktor yang Mempengaruhi Pemakaian Alat Pelindung Diri (APD) pada Pekerja "Stimulasi" di Unit Penderesan PT Socfin Indonesia Tanah Besih Tahun 2014. [Skripsi Ilmiah]. Medan:Fakultas Kesehatan Masyarakat Universitas Sumatera Utara.

Putra, MUK. (2012).Hubungan Tingkat Pengetahuan dan Sikap dengan Perilaku Penggunaan Alat Pelindung Diri pada Mahasiswa Profesi Fakultas Ilmu Keperawatan Universitas Indonesia. [Skripsi 
Ilmiah]. Depok : Fakultas Ilmu Keperawatan Program Sarjana Reguler Universitas Indonesia Usdatinaker.( 2014).Tipe Kecelakaan Kerja di Indonesia Menurut Provinsi Triwulan IV 2014.Soendoro, Adhityo. (2016).Hubungan Pengetahuan, Sikap, Ketersediaan APD dengan Kepatuhan Pemakaian APD Pekerja Bagian Weaving $P T$. Iskandar Indah Printing Textile.[Skripsi Ilmiah]. Surakarta: Universitas Sebelas Maret. 